\title{
Effect of Wet Processing Operations on Functional Properties Imparted to PET Fabrics Loaded with Different Metal Oxides Nanoparticles \\ Part I: Effect of Finishing on Properties Imparted to Bleached PET Fabrics loaded with $\mathrm{TiO}_{2}, \mathrm{ZnO}$ and $\mathrm{SnO}_{2} \mathrm{NPs}$
}

\author{
S.E. Shalaby ${ }^{1}$, N.G. Al-Balakocy ${ }^{1}$, S.M. Abo El-Ola ${ }^{1}$, M.K. Beliakova ${ }^{1}$, A.M. \\ Elshafei $^{2}$ \\ ${ }^{1}$ Textile Research Division, ${ }^{2}$ Division of Genetic Engineering, National Research \\ Centre, Dokki, Cairo, Egypt (Scopus Affiliation ID: 60014618)
}

\begin{abstract}
THE PRESENT article investigates the effect of finishing wet operations on functional properties imparted to bleached and partially hydrolyzed PET fabrics by loading with $\mathrm{TiO}_{2}$ $\mathrm{ZnO}$ and $\mathrm{SnO}_{2}$ nanoparticles. Different trials have been carried out to clarify the effect of the sequences of finishing wet process on the properties of loaded with nanoparticles PET fabrics. Characterization of the so finished fabrics was carried out through SEM, EDX and FT-IR. EDX and FT-IR have confirmed that, interaction has actually taken place between carboxylic groups created on PET fabrics and each of the applied nanoparticles. Moreover, the obtained data revealed that, the finishing wet operation has no effect on the abovementioned interaction. The effect of finishing wet operation on the functional performances of PET fabrics was evaluated by analyzing its antimicrobial activity and ultraviolet protection properties. The antimicrobial activity was tested against B. mycoides, E. coli and C. albicans. It has been found that, loading PET fabrics with $\mathrm{TiO}_{2}$ and $\mathrm{ZnO}$ during or after carrying final finishing process using pad-drycure method paves the way for imparting outstanding antimicrobial activity even after five washing cycles. Also the obtained results revealed that, the sequence of loading the applied NPs before or during or after carrying finishing wet operation highly affect the UPF values.
\end{abstract}

Keywords: PET fabrics, Alkali hydrolysis, Finishing, $\mathrm{TiO}_{2}, \mathrm{ZnO} \mathrm{SnO}_{2} \mathrm{NPs}$, EDX, SEM, FT-IR, Antimicrobial, UPF.

\section{Introduction}

During the last decade the application of metallic oxides nanoparticles has been widely used for imparting different functional performances to textile fabrics [1-17]. Titanium dioxide $\left(\mathrm{TiO}_{2}\right)$, Zinc oxide $(\mathrm{ZnO})$, Tin dioxide $\left(\mathrm{SnO}_{2}\right)$ and nano-Ag were used over the last few years for imparting antimicrobial $[1,4,7,11,12,13,15,16]$, UV blocking $[2,5,8,9]$, self- cleaning $[3,14]$ and photo catalytic [6] activities to textile fibers.

Recently, we have treated polyester (PET) and Nylon -6 fabrics using $\mathrm{TiO}_{2}$ and $\mathrm{ZnO}$ nanoparticles after surface activation by chemical and physical means [13, 16, 17]. The obtained results have revealed that, such modification has imparted to the abovementioned fabrics high antimicrobial and UV protection properties even after repeated washings.
Needless to say that, the properties were imparted on laboratory scale to bleached and partially hydrolyzed PET fabrics [13, 17]. But, the technological and economic factors necessitate the imparting of such properties on the wet processing operations line for bleached, dyed and finished fabrics. Therefore, studying the effect of this sequential pattern of wet processing operations on the gained functional properties is of great importance. This will help to select the most appropriate technological choice to design the complete modified technological line, before starting the production on industrial scale.

Stemming from the abovementioned, the present subject will cover the effect of the wet processing operations on the imparted properties to the PET fabrics. This will be demonstrated in three successive articles. 
The aim of the present article is to investigate the effect of finishing wet operation on functional performances imparted to bleached and partially hydrolyzed PET fabrics by loading with different metal oxides nanoparticles $\left(\mathrm{TiO}_{2}, \mathrm{ZnO}\right.$ and $\left.\mathrm{SnO}_{2}\right)$.

\section{Experimental}

\section{Materials}

Fabrics

Bleached and partially hydrolyzed (carboxylic content $10.9 \mathrm{meq} / 100 \mathrm{gr}$. fabric) polyester woven fabric $(\mathrm{PET} \rightarrow \mathrm{B} \rightarrow \mathrm{H})$ was used throughout this work. PET fabric was kindly supplied by local Egyptian textile companies. These fabrics were partially hydrolyzed using the method reported by Shalaby, etal [20].

\section{Chemicals}

$\mathrm{TiO}_{2}, \mathrm{ZnO}$ nano - emulsions and $\mathrm{SnO}_{2}$ nano - powder were purchased from Sigma -Aldrich. Sodium hydroxide, Sedco finish SMA and nonionic detergent (dispersant agent) were purchased from Fluka and have been used as received.

\section{Microorganisms}

Bacillus mycoides (Gram - positive bacterium), Escherichia coli (Gram - negative bacterium), and Candida albicans (nonfilamentous fungus) were used for estimation of antimicrobial potency of control and treated samples. Microorganisms were obtained from the culture collection of the Department of Microbial Chemistry, Division of Genetic Engineering and Biotechnology, National Research Centre of Egypt.

Modified nutrient agar medium was used and is composed of the following ingredients $(\mathrm{g} / \mathrm{l})$ : peptone (10.0), beef extract (5.0), $\mathrm{NaCl}$ (5.0) and agar (20.0). The $\mathrm{pH}$ was adjusted to 6.8 . This medium was sterilized for $20 \mathrm{~min}$. at $121^{\circ} \mathrm{C}$ under pressure.

\section{Methods}

Preparation of metal oxides NPS

0.5 gr of metal oxides NPs were added in 1 liter of distilled water and subjected to sonication for 30 minutes at room temperature. Nonionic detergent was used as emulsifying agent to enhance the stability of the emulsion.

\section{Loading of $\mathrm{PET} \rightarrow B \rightarrow H$ fabrics with metal oxides NPs}

$\mathrm{PET} \rightarrow \mathrm{B} \rightarrow \mathrm{H}$ fabric samples were immersed in metal oxides NPs colloidal solutions, squeezed to the required pickup increase, dried at $100{ }^{\circ} \mathrm{C}$ for 60 minutes. and then cured at $150{ }^{\circ} \mathrm{C}$ for 10 minutes in case of loading with $\mathrm{TiO}_{2}$ and $\mathrm{ZnO}$

Egypt. J. Chem. 60, No. 6 (2017) and at $130{ }^{\circ} \mathrm{C}$ for 5 minutes in case of $\mathrm{SnO}_{2}$. The PET loaded samples were then washed with distilled water to remove NPs that did not attach to the fabrics surfaces. In order to evaluate NPs adhesion to PET textiles, the loaded fabrics were repeatedly washed for five cycles according to the standard AATCC test method (61-1989).

\section{Finishing (softening)}

$\mathrm{PET} \rightarrow \mathrm{B} \rightarrow \mathrm{H}$ fabrics have been immersed in finishing solution (Sedco Finish SMA) (20g/l), squeezed, dried at $100^{\circ} \mathrm{C}$, and cured at $160^{\circ} \mathrm{C}$ for 3.0 minutes.

Analysis

\section{Carboxylic content}

Carboxylic content was determined according to the method described by Daul, et al [21].

\section{Antimicrobial activity}

Antimicrobial activity of $\mathrm{PET} \rightarrow \mathrm{B} \rightarrow \mathrm{H}$ fabrics loaded with metal oxides NPs was quantified using shake flask method. In this method the antimicrobial activity of immobilized antimicrobial agents is determined under dynamic contact conditions according to ASTM standard test method 2143 (2001).

\section{Scan Electron Microscope (SEM)}

Fabrics morphology was characterized by scanning electron microscope (SEM) (JEOLModel TSM T20).

Electron Dispersion Emission X-ray (EDX)

Electron Dispersion Emission X-Ray (EDX) mode was applied for the elemental composition analysis. Gold layer was deposited on the samples before analysis.

\section{Fourier Transformation Infrared (FT-IR)}

The chemical structure was determined using the Fourier transformation infrared (FT-IR) spectrometer, model NEXUS 670, NICOLET USA. The measurements were carried in the spectral range from $4000 \mathrm{~cm}^{-1}$ to $500 \mathrm{~cm}^{-1}$. Reflection percentage measurement technique was applied ( $\mathrm{R} \%)$. All investigated samples have the same area and weight.

\section{Ultraviolet Protection Factor (UPF)}

Ultraviolet Protection Factor (UPF) was determined using UV- Shimadzu 3101 P C spectrophotometer. It is a double beam direct ratio measuring system. It consists of the photometer unit and a PC computer. UPF factor was determined according to the method described in Australian/New Zealand standard AS/NZS 4399: 1996. UPF values were calculated automatically and classified according to Table A. 
TABLE (A). Protection and classification according to AS/NZS 4399:1966.

\begin{tabular}{|c|c|}
\hline UVP & UPF \\
\hline Excellent & $40,45,50,50+$ \\
\hline Very good & $25,30,35$ \\
\hline Good & 15,20 \\
\hline Non-Rateable & $0,5,10$ \\
\hline
\end{tabular}

\section{$\underline{\text { Results and Discussion }}$}

Different trials have been carried out to clarify the effect of the sequences of finishing wet process operation on the properties of bleached and partially hydrolyzed PET fabrics loaded with NPs, as follows:

1. hydrolyzed fabrics $(\mathrm{PET} \rightarrow \mathrm{B} \rightarrow \mathrm{H})$ were separately immersed in $\mathrm{TiO}_{2}, \mathrm{ZnO}$, and $\mathrm{SnO}_{2}$ emulsions, squeezed to $75 \%$ pick up increase, dried at $100^{\circ} \mathrm{C}$ for $60 \mathrm{~min}$ and cured at $150^{\circ} \mathrm{C}$ for 10 minutes. The loaded fabrics were then washed with distilled water to remove the metal oxide NPs that did not attach to the fabric surface, and were finally evaluated.

$$
\begin{aligned}
& \mathrm{PET} \rightarrow \mathrm{B} \rightarrow \mathrm{H} \rightarrow \mathrm{TiO}_{2} \\
& \mathrm{PET} \rightarrow \mathrm{B} \rightarrow \mathrm{H} \rightarrow \mathrm{SnO}_{2}
\end{aligned}
$$

2. $\mathrm{PET} \rightarrow \mathrm{B} \rightarrow \mathrm{H}$ fabrics have been immersed in finishing solution, squeezed to constant pick up increase in weight, dried at $100 \mathrm{oC}$ and finally cured at $160^{\circ} \mathrm{C}$ for 3 minutes. The obtained fabrics were then washed and evaluated. (PET $\rightarrow \mathrm{B} \rightarrow \mathrm{H} \rightarrow \mathrm{F}$ )

3. The PET fabrics which have been prepared in trail (2) were separately treated in water emulsions of each of $\mathrm{TiO}_{2}, \mathrm{ZnO}$ and $\mathrm{SnO}_{2} \mathrm{NPs}$ according to the conditions and sequences listed in trial (1). The obtained fabrics were washed and evaluated.

$$
\begin{aligned}
& \mathrm{PET} \rightarrow \mathrm{B} \rightarrow \mathrm{H} \rightarrow \mathrm{F} \rightarrow \mathrm{TiO}_{2} \quad \mathrm{PET} \rightarrow \mathrm{B} \rightarrow \mathrm{H} \rightarrow \mathrm{F} \rightarrow \mathrm{ZnO} \\
& \mathrm{PET} \rightarrow \mathrm{B} \rightarrow \mathrm{H} \rightarrow \mathrm{F} \rightarrow \mathrm{SnO}_{2}
\end{aligned}
$$

4. Each of $\mathrm{PET} \rightarrow \mathrm{B} \rightarrow \mathrm{H}$ fabrics was treated in a bath containing at the same time the finishing agent and each of $\mathrm{TiO}_{2}, \mathrm{ZnO}$ and $\mathrm{SnO}_{2}$ emulsions. The fabrics were then treated according to the same sequences and conditions used in trial (1).
$\mathrm{PET} \rightarrow \mathrm{B} \rightarrow \mathrm{H} \rightarrow\left(\mathrm{F}+\mathrm{TiO}_{2}\right) \quad \mathrm{PET} \rightarrow \mathrm{B} \rightarrow \mathrm{H} \rightarrow(\mathrm{F}+\mathrm{ZnO})$

$\mathrm{PET} \rightarrow \mathrm{B} \rightarrow \mathrm{H} \rightarrow\left(\mathrm{F}+\mathrm{SnO}_{2}\right)$

5. PETBH Fabrics were loaded, separately, with each of $\mathrm{TiO}_{2}, \mathrm{ZnO}, \mathrm{SnO}_{2}$ emulsions according to sequences and conditions used in trail (1). Then these fabrics were finally finished as listed in trial (2), washed, and evaluated.

$$
\begin{aligned}
& \mathrm{PET} \rightarrow \mathrm{B} \rightarrow \mathrm{H} \rightarrow \mathrm{TiO}_{2} \rightarrow \mathrm{F} \quad \mathrm{PET} \rightarrow \mathrm{B} \rightarrow \mathrm{H} \rightarrow \mathrm{ZnO} \rightarrow \mathrm{F} \\
& \mathrm{PET} \rightarrow \mathrm{B} \rightarrow \mathrm{H} \rightarrow \mathrm{SnO}_{2} \rightarrow \mathrm{F}
\end{aligned}
$$

Characterization of $P E T \rightarrow B \rightarrow H$ fabrics loaded with $\mathrm{TiO}_{2}, \mathrm{ZnO}$ and $\mathrm{SnO}_{2} \mathrm{NPS}$ at different conditions

We have mentioned before that, the present work aims to clarify the effect of finishing wet operation on the functional properties imparted to bleached, partially hydrolyzed and loaded with different NPs polyester fabrics. Therefore, characterization of the so finished fabrics seems to be of great importance to confirm that interaction has actually taken place between carboxylic groups created on PET fabrics and each of the used NPs. This was carried out through Electron Dispersion Emission X-ray (EDX), Scanning Electron Microscope (SEM) and FT-IR measurements.

Electron Dispersion Emission X-ray ( EDX)

SEM analysis performed in EDX mode was used to confirm the presence of the applied NPs on the PET fabrics, loaded with $\mathrm{TiO}_{2}, \mathrm{ZnO}$ and $\mathrm{SnO}_{2}$ NPs, following the washing step, are shown in Fig. (1-3).The obtained results confirm the existence of metallic $\mathrm{Ti}, \mathrm{Zn}$ and $\mathrm{Sn}$, irrespective of the mode and sequences of carrying out loading and finishing operations. It was found that the fabrics still contain Ti, Zn and Sn even after five standard washing cycles (Table1). Data listed in Table 1 also reveal higher $\mathrm{Zn}$ and $\mathrm{Sn}$ contents on $\mathrm{PET} \rightarrow \mathrm{B} \rightarrow \mathrm{H}$ fabrics. Based on the abovementioned, one can conclude that the finishing wet operation has no effect on the interaction between the carboxylic groups and the metal oxides NPs

\section{Scan Electron Microscope (SEM)}

The surface topography of $\mathrm{PET} \rightarrow \mathrm{B} \rightarrow \mathrm{H}$ fabrics loaded with metal oxides NPs and finished was investigated using SEM technique. The obtained results (Fig. 1, 2, 3) reveal the following:

1 - $\mathrm{PET} \rightarrow \mathrm{B} \rightarrow \mathrm{H}$ fabrics are characterized by rough surfaces with pits [Fig. 1, 2, 3 (a)] 


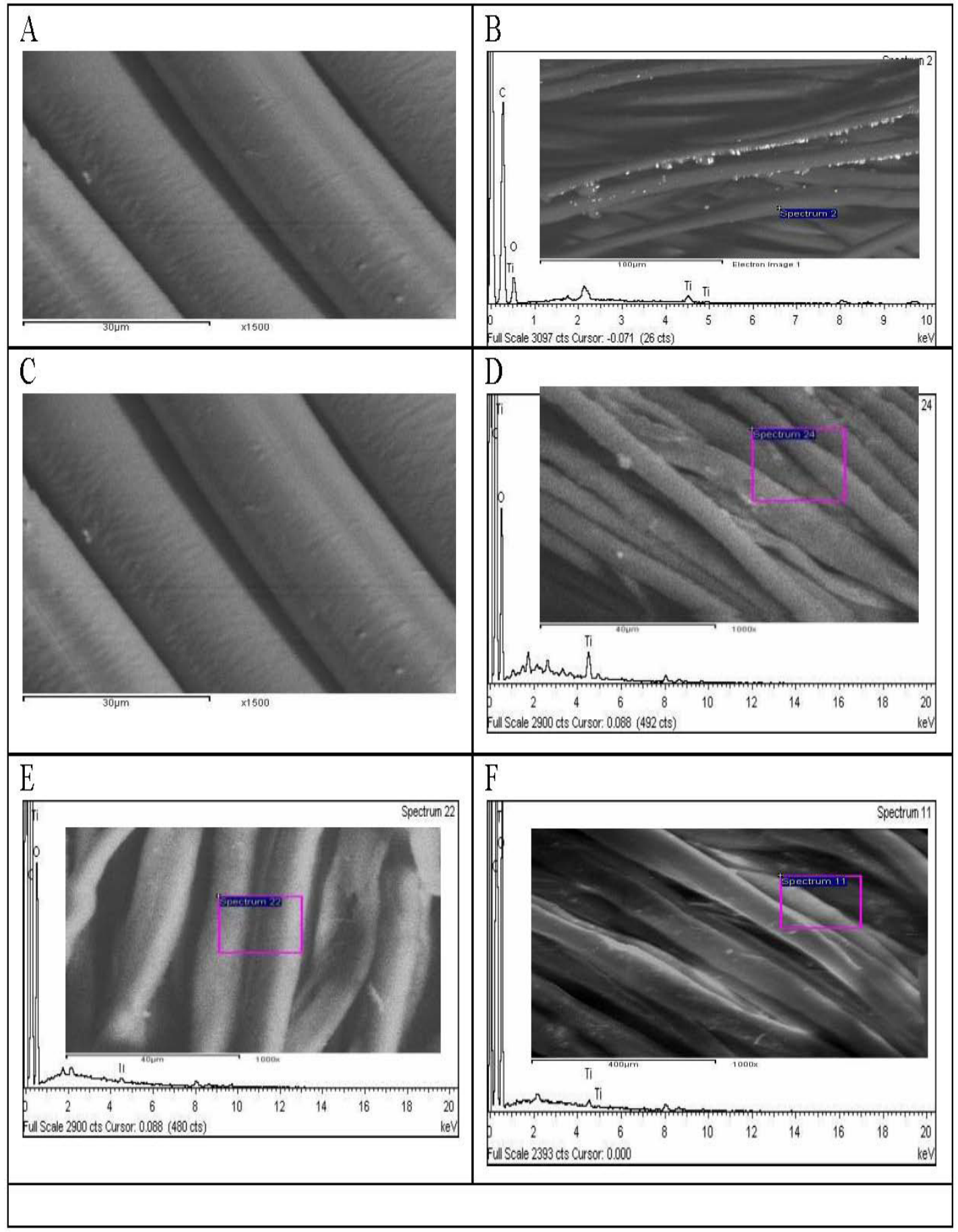

Fig. 1. SEM and EDX micrographs of bleached and partially hydrolyzed PET fabrics loaded with $\mathrm{TiO}_{2} \mathrm{NPs}^{*}$ (X2000).
[A] PET $\rightarrow$ B $\rightarrow$ H (Blank)
$[\mathrm{B}] \mathrm{PET} \rightarrow \mathrm{B} \rightarrow \mathrm{H} \rightarrow \mathrm{TiO}_{2}$
$[\mathrm{C}]$ PET $\rightarrow \mathrm{B} \rightarrow \mathrm{H} \rightarrow \mathrm{F}$ (Blank)
$[\mathrm{D}] \mathrm{PET} \rightarrow \mathrm{B} \rightarrow \mathrm{H} \rightarrow \mathrm{F} \rightarrow \mathrm{TiO}_{2}[\mathrm{E}] \mathrm{PET} \rightarrow \mathrm{B} \rightarrow \mathrm{H} \rightarrow\left(\mathrm{F}+\mathrm{TiO}_{2}\right) \quad[\mathrm{F}] \mathrm{PET} \rightarrow \mathrm{B} \rightarrow \mathrm{H} \rightarrow \mathrm{TiO}_{2} \rightarrow \mathrm{F}$
*After five Washing Cycle; AATCC Test Method (61-1989).

Egypt. J. Chem. 60, No. 6 (2017) 


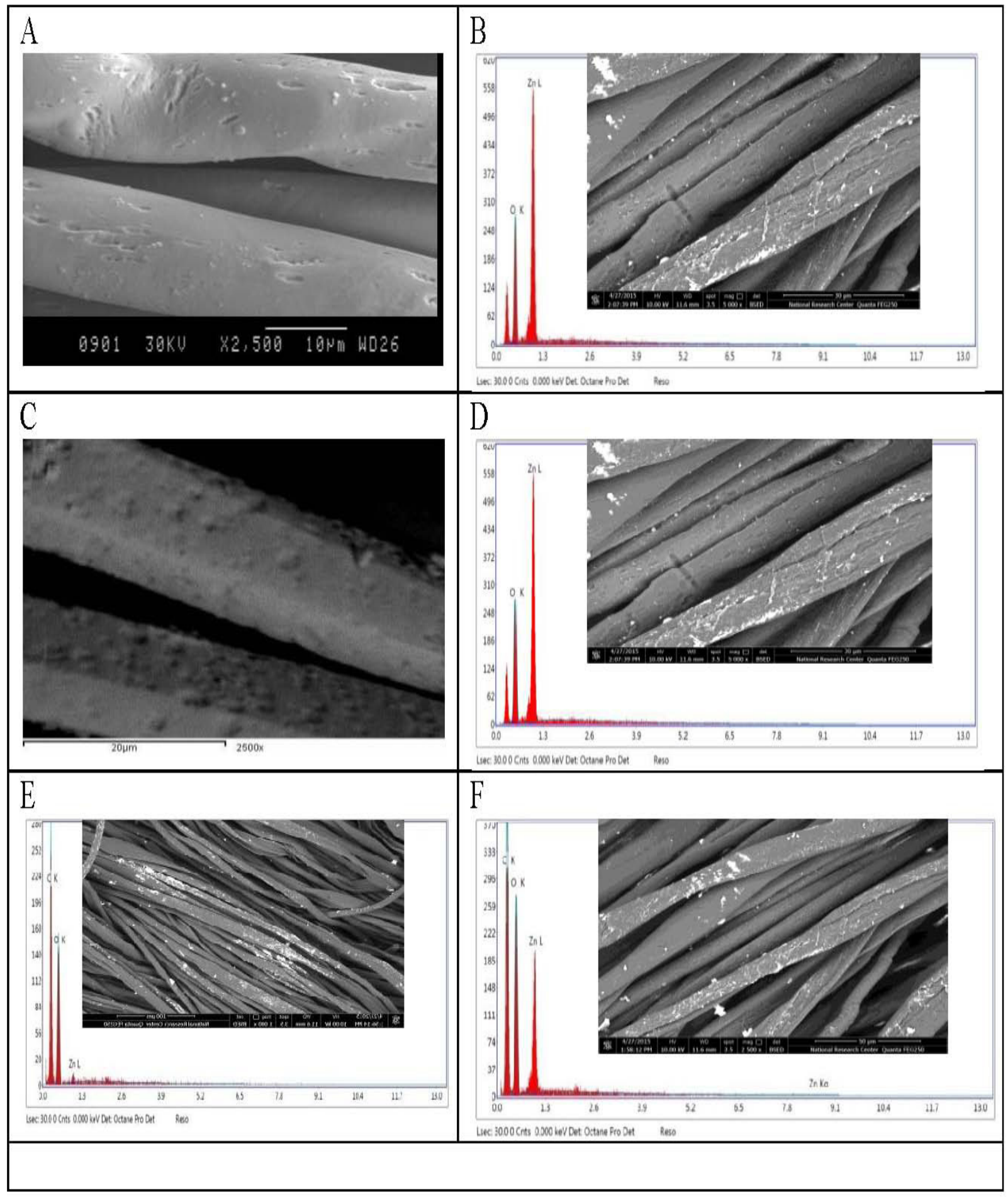

Fig. 2. SEM and EDX micrographs of bleached and partially hydrolyzed PET fabrics loaded with ZnO NPs* (X2000).

$[\mathrm{A}]$ PET $\rightarrow \mathrm{B} \rightarrow \mathrm{H}$ (Blank) $\quad[\mathrm{B}]$ PET $\rightarrow \mathrm{B} \rightarrow \mathrm{H} \rightarrow \mathrm{ZnO} \quad[\mathrm{C}]$ PET $\rightarrow \mathrm{B} \rightarrow \mathrm{H} \rightarrow \mathrm{F}$ (Blank) $[\mathrm{D}] \mathrm{PET} \rightarrow \mathrm{B} \rightarrow \mathrm{H} \rightarrow \mathrm{F} \rightarrow \mathrm{ZnO} \quad[\mathrm{E}] \mathrm{PET} \rightarrow \mathrm{B} \rightarrow \mathrm{H} \rightarrow(\mathrm{F}+\mathrm{ZnO}) \quad[\mathrm{F}] \mathrm{PET} \rightarrow \mathrm{B} \rightarrow \mathrm{H} \rightarrow \mathrm{ZnO} \rightarrow \mathrm{F}$ *After Five Washing Cycles; AATCC Test Method (61-1989). 


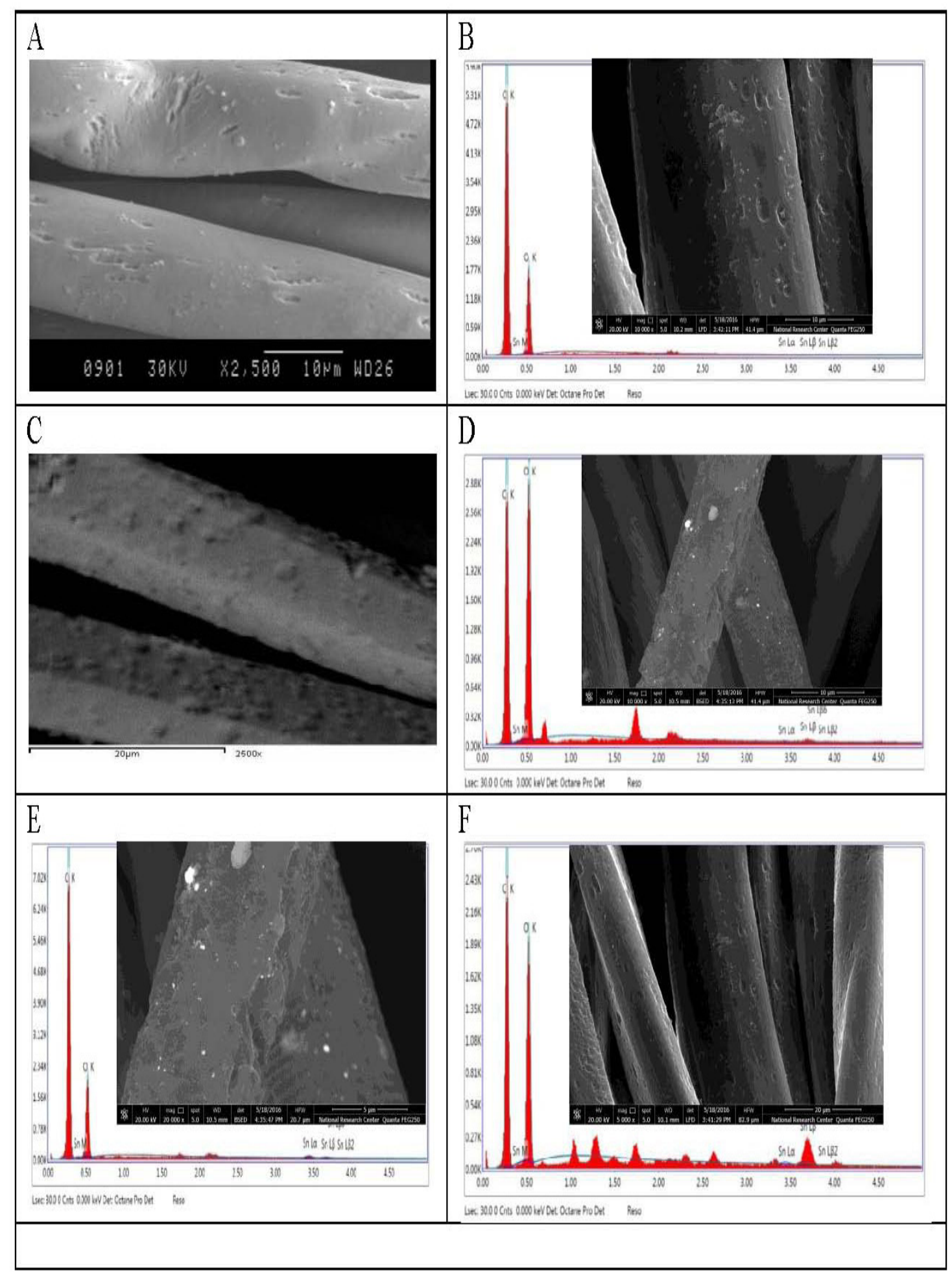

Fig. 3. SEM and EDX micrographs of bleached and partially hydrolyzed PET fabrics loaded with $\mathrm{SnO}_{2} \mathrm{NPs}^{*}$ (X2000).
[A] PET $\rightarrow \mathrm{B} \rightarrow \mathrm{H}$ (Blank)
$[\mathrm{B}] \mathrm{PET} \rightarrow \mathrm{B} \rightarrow \mathrm{H} \rightarrow \mathrm{SnO}_{2}$
$[\mathrm{C}] \mathrm{PET} \rightarrow \mathrm{B} \rightarrow \mathrm{H} \rightarrow \mathrm{F}$ (Blank)
$[\mathrm{D}] \mathrm{PET} \rightarrow \mathrm{B} \rightarrow \mathrm{H} \rightarrow \mathrm{F} \rightarrow \mathrm{SnO}_{2} \quad[\mathrm{E}] \mathrm{PET} \rightarrow \mathrm{B} \rightarrow \mathrm{H} \rightarrow\left(\mathrm{F}+\mathrm{SnO}_{2}\right) \quad[\mathrm{F}] \mathrm{PET} \rightarrow \mathrm{B} \rightarrow \mathrm{H} \rightarrow \mathrm{SnO}_{2} \rightarrow \mathrm{F}$
*After Five Washing Cycles; AATCC Test Method (61-1989).

Egypt. J. Chem. 60, No. 6 (2017) 
2- Treatment of $\mathrm{PET} \rightarrow \mathrm{B} \rightarrow \mathrm{H}$ fabrics with $\mathrm{TiO}_{2}$, $\mathrm{ZnO}, \mathrm{SnO}_{2}$ NPs emulsions using pad- dry -cure method leads to the formation of some precipitation on the surfaces [Fig. 1,2,3- (b)]

3- Finishing of $\mathrm{PET} \rightarrow \mathrm{B} \rightarrow \mathrm{H}$ leads to obtain fabric surfaces characterized by less roughness and pits compared with unfinished ones [Fig.1, 2, 3- (c)]

4- Carrying out treatment with the applied metal oxides NPs emulsions after finishing wet operation leads to increase the density of the thin layer formed on the surface of fabrics [Fig. 1, 2, 3-(d)]

5-Carrying out the loading and finishing operations at the same time leads to an increase of the thin layer formed on the surface. In addition to this, such treatment paves the way for filling the pits formed after partial hydrolysis with alkali [Fig.1, 2, 3-(e)]. The same holds true in case of carrying out the finishing wet operation after loading with metal oxides NPs [Fig. 1 2, 3- (f)].
6-It is worth mentioning that, carrying out finishing wet operation followed by loading with metal oxide NPs with pad- dry- cure method leads to get fabrics with more homogeneous and smooth fabric surfaces compared with that obtained after loading with NPs followed by finishing wet operation.

The abovementioned changes which took place on the surface topography of $\mathrm{PET} \rightarrow \mathrm{B} \rightarrow \mathrm{H}$ fabrics loaded with $\mathrm{TiO}_{2}, \mathrm{ZnO}$, and $\mathrm{SnO}_{2} \mathrm{NPs}$ and finished are a direct indication that these NPs are attached to the fabric surfaces.

\section{Fourier Transformation Infrared (FT-IR)}

Data in Table 2 show the effect of finishing wet operation on FT-IR absorption bands of functional groups in bleached and partially hydrolyzed PET fabrics loaded with different metal oxides NPs. Based on these data one can conclude the following:

In the case of loading with $\mathrm{TiO}_{2} \mathrm{NPS}$

The finishing of PET $\rightarrow \mathrm{B} \rightarrow \mathrm{H}$ fabrics did not affect the absorption bands of $>\mathrm{C}=\mathrm{O}$ groups, but caused a slight decrease in its intensities (from $87.7 \%$-Table 3 to $85.6 \%$ - Table 2).

TABLE 1. Ti, $\mathrm{Zn}$ and Sn content on the surfaces of bleached and partially hydrolyzed PET fabrics loaded withTiO, $\mathrm{ZnO}$ and $\mathrm{SnO}_{2} \mathrm{NPs}$.

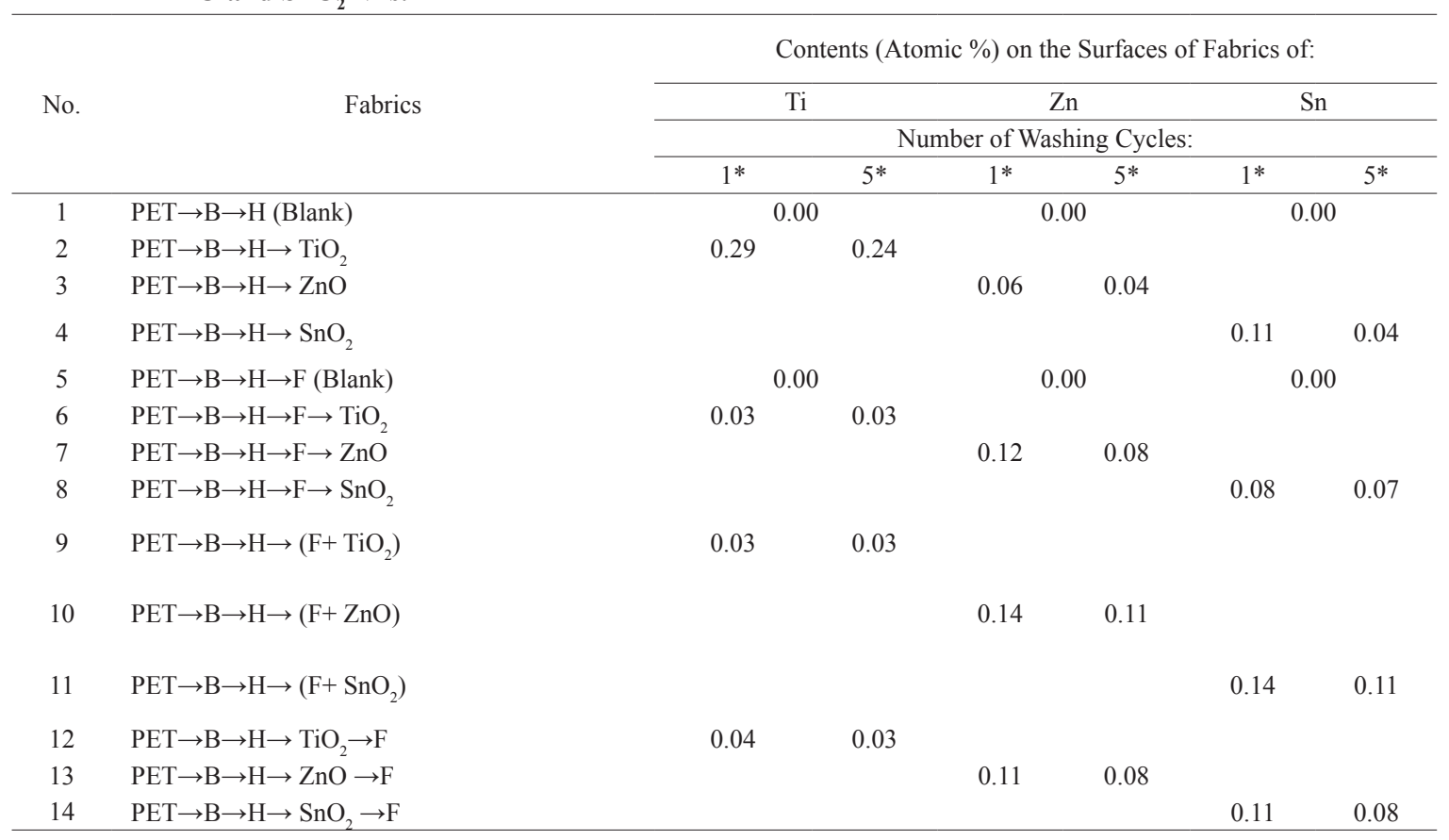

$\mathrm{B}=$ Bleached $\mathrm{H}=$ Partially Hydrolyzed $\mathrm{F}=$ Finished

Treatment Conditions: Pad-dry-cure Method

$\left[\mathrm{TiO}_{2}\right]$ and $[\mathrm{ZnO}], 0.5 \%$; Curing Temperature, $150^{\circ} \mathrm{C}$; Curing Time, $10 \mathrm{~min}$.,

$\left[\mathrm{SnO}_{2}\right], 0.5 \%$; Curing Temperature, $130^{\circ} \mathrm{C}$; Curing Time, 5 min.,

Finishing Conditions:

[Sedco Finish], $20.0 \mathrm{~g} / 1$; Curing Temperature, $160^{\circ} \mathrm{C}$; Curing Time, $3.0 \mathrm{~min}$.,

* After 1 and 5 washing Cycles; AATCC Test Method (61-1989). 
The loading of finished fabrics ( $\mathrm{PET} \rightarrow \mathrm{B} \rightarrow \mathrm{H} \rightarrow \mathrm{F}$ ) with $\mathrm{TiO}_{2} \mathrm{NPs}$ did not affect the absorption bands position of the carbonyl group, irrespective of the loading position with the above mentioned NPs before or during or after the finishing wet operation. However, the loading of such fabrics caused only a little drop in the intensity of the absorption band to $85.6 \%$ (Table 2) compared with $89 \%$ for the unfinished loaded with the same NPs (Table 3). The data listed in Table 2 point to that , the loading $\mathrm{PET} \rightarrow \mathrm{B} \rightarrow \mathrm{H}$ fabrics during or before carrying out the finishing wet operation results in increasing the intensity of $>\mathrm{C}=\mathrm{O}$ group.

TABLE 2. Effect of finishing on ft-ir absorption bands of functional groups in bleached and partially hydrolyzed PET fabrics loaded with metal oxides NPs.

\begin{tabular}{|c|c|c|c|c|c|c|c|}
\hline \multirow[t]{3}{*}{ No. } & \multirow[t]{3}{*}{ Fabrics } & \multicolumn{4}{|c|}{$\begin{array}{c}\text { Absorption Bands and Intensities of }>\mathrm{C}=\mathrm{O} \text { and } \mathrm{OH} \\
\text { groups after finishing } \\
\mathrm{PET} \rightarrow \mathrm{B} \rightarrow \mathrm{H} \text { fabrics loaded with } \\
\text { metal oxides NPs }\end{array}$} & \multicolumn{2}{|c|}{$\begin{array}{c}\text { New Absorption Bands } \\
\text { Appeared }\end{array}$} \\
\hline & & \multicolumn{2}{|c|}{$>\mathrm{C}=\mathrm{O}$} & \multicolumn{2}{|c|}{$-\mathrm{OH}$} & & \\
\hline & & $\begin{array}{l}\text { Position } \\
\left(\mathrm{Cm}^{-1}\right)\end{array}$ & $\begin{array}{c}\text { Intensity } \\
(\%)\end{array}$ & $\begin{array}{l}\text { Position } \\
\left(\mathrm{Cm}^{-1}\right)\end{array}$ & $\begin{array}{c}\text { Intensity } \\
(\%)\end{array}$ & $\begin{array}{l}\text { Position } \\
\left(\mathrm{Cm}^{-1}\right)\end{array}$ & $\begin{array}{c}\text { Intensity } \\
(\%)\end{array}$ \\
\hline 3 & $\mathrm{PET} \rightarrow \mathrm{B} \rightarrow \mathrm{H} \rightarrow\left(\mathrm{F}+\mathrm{TiO}_{2}\right)$ & 1713.0 & 87.6 & 3502.6 & 99.7 & 802.2 & 92.1 \\
\hline 4 & $\mathrm{PET} \rightarrow \mathrm{B} \rightarrow \mathrm{H} \rightarrow \mathrm{TiO}_{2} \rightarrow \mathrm{F}$ & 1713.1 & 90.1 & 3676.0 & 99.8 & 809.8 & 96.0 \\
\hline 5 & $\mathrm{PET} \rightarrow \mathrm{B} \rightarrow \mathrm{H} \rightarrow \mathrm{F}$ & 1743.3 & 49.0 & 3431.7 & 46.3 & - & - \\
\hline 6 & $\mathrm{PET} \rightarrow \mathrm{B} \rightarrow \mathrm{H} \rightarrow \mathrm{F} \rightarrow \mathrm{ZnO}$ & 1739.5 & 47.0 & 3431.7 & 48.4 & 633.5 & 85.6 \\
\hline 9 & $\mathrm{PET} \rightarrow \mathrm{B} \rightarrow \mathrm{H} \rightarrow \mathrm{F}$ & 1710.6 & 46.2 & 3554.2 & 92.7 & - & - \\
\hline 10 & $\mathrm{PET} \rightarrow \mathrm{B} \rightarrow \mathrm{H} \rightarrow \mathrm{F} \rightarrow \mathrm{SnO}_{2}$ & 1710.6 & 46.2 & 3426.9 & 91.9 & 435.8 & 95.5 \\
\hline 11 & $\mathrm{PET} \rightarrow \mathrm{B} \rightarrow \mathrm{H} \rightarrow\left(\mathrm{F}+\mathrm{SnO}_{2}\right)$ & 1710.6 & 39.6 & 3426.9 & 88.9 & 436.9 & 92.5 \\
\hline 12 & $\mathrm{PET} \rightarrow \mathrm{B} \rightarrow \mathrm{H} \rightarrow \mathrm{SnO}_{2} \rightarrow \mathrm{F}$ & 1711.5 & 39.3 & 3430.7 & 67.9 & 433.0 & 90.6 \\
\hline
\end{tabular}

PET = Polyester Fabric $\quad B=$ Bleached $\quad \mathrm{H}=$ Partially Hydrolyzed $\quad \mathrm{F}=$ Finished

Treatment Conditions: Pad-Dry-Cure Method

$\left[\mathrm{TiO}_{2}\right]$ and $[\mathrm{ZnO}], 0.5 \%$; Curing Temperature, $150^{\circ} \mathrm{C}$; Curing Time, $10 \mathrm{~min}$., $\left[\mathrm{SnO}_{2}\right], 0.5 \%$; Curing Temperature, $130^{\circ} \mathrm{C}$; Curing Time, 5 min.,

Finishing Conditions:

[Sedco Finish], 20g/l; Curing Temperature, $160^{\circ} \mathrm{C}$; Curing Time, $3 \mathrm{~min}$.

* After 1Washing Cycle; AATCC Test Method (61-1989).

TABLE 3. FT-IR absorption bands of functional groups in bleached and partially hydrolyzed PET fabrics loaded with metal oxide NPs.

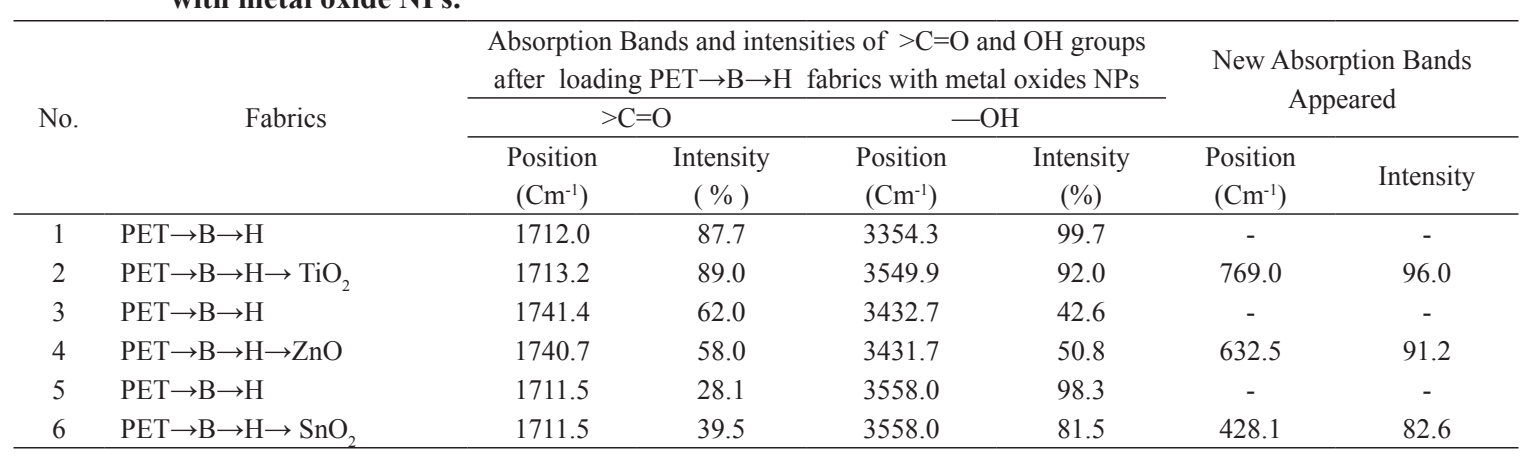

PET $=$ Polyester Fabric $\quad \mathrm{B}=$ Bleached $\quad \mathrm{H}=$ Partially Hydrolyzed $\quad \mathrm{F}=$ Finished

Treatment Conditions:Pad-Dry-Cure Method

$\left[\mathrm{TiO}_{2}\right]$ and $[\mathrm{ZnO}], 0.5 \%$; Curing Temperature, $150^{\circ} \mathrm{C}$; Curing Time, $10 \mathrm{~min} .\left[\mathrm{SnO}_{2}\right], 0.5 \%$; Curing Temperature, $130^{\circ} \mathrm{C}$; Curing Time, 5min.,

* After 1Washing Cycle; AATCC Test Method (61-1989).

Egypt. J. Chem. 60, No. 6 (2017) 
The finishing of $\mathrm{PET} \rightarrow \mathrm{B} \rightarrow \mathrm{H}$ fabrics leads to a noticeable shift towards higher frequencies of the $\mathrm{OH}$ group (Table 2) in comparison with the unfinished fabrics (Table 3). The maximum shift of frequencies of this group reached its top value after finishing and loading with $\mathrm{TiO}_{2}$ $\mathrm{NPs}\left(\mathrm{PET} \rightarrow \mathrm{B} \rightarrow \mathrm{H} \rightarrow \mathrm{F} \rightarrow \mathrm{TiO}_{2}\right.$ ). The frequencies shifted from $3549.9 \mathrm{~cm}^{-1}$ (Table 3 ) in case of $\mathrm{PET} \rightarrow \mathrm{B} \rightarrow \mathrm{H} \rightarrow \mathrm{TiO}_{2}$ to $3749.8 \mathrm{~cm}^{-1}$ in case of finished and loaded with $\mathrm{TiO}_{2}$ NPs fabrics (Table 2). At the same time, this was accompanied with a decrease in the intensity of - $\mathrm{OH}$ group from $92 \%$ (Table 3) to $85.9 \%$ (Table 2). Data listed in Table 2 , also indicate that, loading $\mathrm{PET} \rightarrow \mathrm{B} \rightarrow \mathrm{H} \rightarrow \mathrm{F}$ with $\mathrm{TiO}_{2} \mathrm{NPs}$, before or during carrying out the finishing operation leads to an increase in the intensity of this group, compared with that in case of loading with the same NPs after the finishing operation.

The FT-IR spectra of all fabrics finished and loaded with $\mathrm{TiO}_{2} \mathrm{NPs}$ show the appearance of new absorption bands in the range of $783.3 \mathrm{~cm}^{-1}$ to $809.8 \mathrm{~cm}^{-1}$ which characterizes the formation of bonding (Ti-O-C) irrespective of the loading position of NPs (Table 2).

\section{In the case of loading with $\mathrm{ZnONPS}$}

Results shown in Table 2 reveal that, the absorption bands of carbonyl group in all fabrics loaded with ZnO NPs did not change its position. Contrary to this, the intensity of such group has increased especially in the case of fabrics loaded with ZnO NPs before or during finishing operation (Table 2). The same holds true in case of the position and the intensity of the $\mathrm{OH}$-group.

The FT-IR spectra of all fabrics loaded with $\mathrm{ZnO}$ NPs and finished show the appearance of new absorption bands in the range of $631.8 \mathrm{~cm}^{-1}$ to $635.1 \mathrm{~cm}^{-1}$ which characterizes the formation of new bonding ( $\mathrm{Zn}-\mathrm{O}-\mathrm{C})$ irrespective of the position of loading NPs (Table 2).

In the case of loading with $\mathrm{SnO}_{2} \mathrm{NPS}$

It was found (Table 2) that, the wave length of carbonyl group in all fabrics loaded with $\mathrm{SnO}_{2}$ NPs did not change its position. On the contrary, this was accompanied with a decrease in the intensity of this group reaching its maximum in the case of loading the fabrics before or during carrying out the finishing operation. The same holds true in case of the position and the intensity of the $\mathrm{OH}^{-}$group. Moreover, it was found that the maximum decrease in $\mathrm{OH}^{-}$group intensity takes place in case of loading fabrics with $\mathrm{SnO}_{2}$ before carrying out the finishing operation.
The FT- IR spectra of all fabrics loaded with $\mathrm{SnO}_{2} \mathrm{NPs}$ and finished confirm the appearance of new absorption bands in the range of $433.0 \mathrm{~cm}^{-1}$ to $436.9 \mathrm{~cm}^{-1}$ which characterizes the formation of bonding (Sn-O-C) irrespective of the loading position of $\mathrm{SnO}_{2} \mathrm{NPs}$ [22].

Stemming from the abovementioned one can conclude that, the $\mathrm{C}=\mathrm{O}$ and $\mathrm{OH}^{-}$groups are affected as a result of loading $\mathrm{PET} \rightarrow \mathrm{B} \rightarrow \mathrm{H} \rightarrow \mathrm{F}$ with metal oxides $\left(\mathrm{TiO}_{2}, \mathrm{ZnO}\right.$ and $\left.\mathrm{SnO}_{2} \mathrm{NPs}\right)$. This happens irrespective of the nature of loaded NPs and the sequences of the loading process: after alkali treatment, or during or after or before carrying out finishing operation. In addition to this, the carboxylate groups, created on the fabrics surface after alkali treatment reacted with NPs forming a new chemical bond with such NPs. Similar findings have been reported [23].

The effect of finishing on functional performances imparted to bleached PET fabrics loaded with different NPs

Antimicrobial activity

The antimicrobial activity of bleached and partially hydrolysed $(\mathrm{PET} \rightarrow \mathrm{B} \rightarrow \mathrm{H})$ fabrics loaded with $\mathrm{TiO}_{2}, \mathrm{ZnO}$ and $\mathrm{SnO}_{2} \mathrm{NPs}$ was evaluated by deterring the reduction percentage of Grampositive (Bacillus mycoides) Gram negative (Escherichia Coli), and nonfilamentous fungs (Candida albicans) bacteria using the shake flask method. Data given in Table 4 illustrate the effect of finishing wet operation, the sequences used for loading the fabrics with NPs and the repeating washing on the percentages of colony forming units $(\% \mathrm{CFU})$ reduction on the above mentioned fabrics. Based on the data given in Table 4, one can conclude the following:

1- In general, the loading of $\mathrm{TiO}_{2}, \mathrm{ZnO}$ and $\mathrm{SnO}_{2}$ NPs on $(\mathrm{PET} \rightarrow \mathrm{B} \rightarrow \mathrm{H})$ fabrics, led to the reduction of microbes on the surface of fabrics. This reduction depends on the nature of NPs, the sequences of loading, and the resistance towards repeated washings.

2- It was found that the sequence of loading with the above mentioned NPs during wet processing operations for PET fabrics plays a pivotal role. This conclusion is based on the following:

a) The obtained results revealed that, CFU of the fabrics loaded with $\mathrm{TiO}_{2}$ after alkali treatment has reached after five repeated standard washing cycles $36 \%, 52 \%, 36 \%$ in case of B.

Egypt. J. Chem. 60, No. 6 (2017) 
mycod, E. Coli and C. albicans respectively.

This is in contrast with $68 \%, 38 \%, 63 \%$, respectively, in case of $\mathrm{ZnO}$ loading. At the same time, the loading with $\mathrm{SnO}_{2} \mathrm{NPs}$ exhibits much lower effect than in case of $\mathrm{TiO}_{2}$ and $\mathrm{ZnO}$ NPs.

b) The loading of $\mathrm{TiO}_{2}$ and $\mathrm{ZnO}$ NPs using paddry- cure method after or during finishing operation, led to obtaining PET fabrics with $100 \%$ CFU reduction after one standard washing cycle with respect to the above mentioned three types of bacteria. It is worth mentioning that, the repeated washings of such fabrics did not cause a noticeable decrease in its ability for reduction of microbes. The data listed in Table 4 illustrate that after 5 washing cycles, the fabrics still acquire excellent CFU reduction towards $\underline{B} \cdot \underline{m}$ and $\underline{E} . \underline{C}$. On the contrary, the application of $\mathrm{SnO}_{2} \mathrm{NPs}$ did not cause any noticeable improvement in the antimicrobial activity of such fabrics in comparison with those obtained after loading with such NPs directly after alkali treatment.

c) The loading of $\mathrm{TiO}_{2}$ and $\mathrm{ZnO}$ NPs on PET fabrics before carrying out the finishing operation also leads to imparting antimicrobial properties to a lesser extent compared with those obtained after loading during or after finishing operation (Table 4). It was found that, the antimicrobial activity of PET fabrics loaded with $\mathrm{SnO}_{2}$ NPs before finishing process continues to decrease.

Based on the above mentioned, we can conclude that, the best method for loading bleached and partially hydrolyzed PET fabrics with $\mathrm{TiO}_{2}$ and $\mathrm{ZnO}$ NPs for imparting high antimicrobial activity even after repeated washings should follow the sequence:

1- Bleaching PET fabrics using standard method;

2- Partial hydrolysis of fabrics using $\mathrm{NaOH}$ water solutions;

3- Loading bleached and partially hydrolyzed PET fabrics with $\mathrm{TiO}_{2}$ and $\mathrm{ZnO}$ during or after

TABLE 4. Antimicrobial activity of bleached and partially hydrolyzed $\mathrm{PET}$ fabrics loaded with $\mathrm{TiO}_{2}, \mathrm{ZnO}$ and $\mathrm{SnO}_{2} \mathrm{NPs}$, determined by shake flask method.

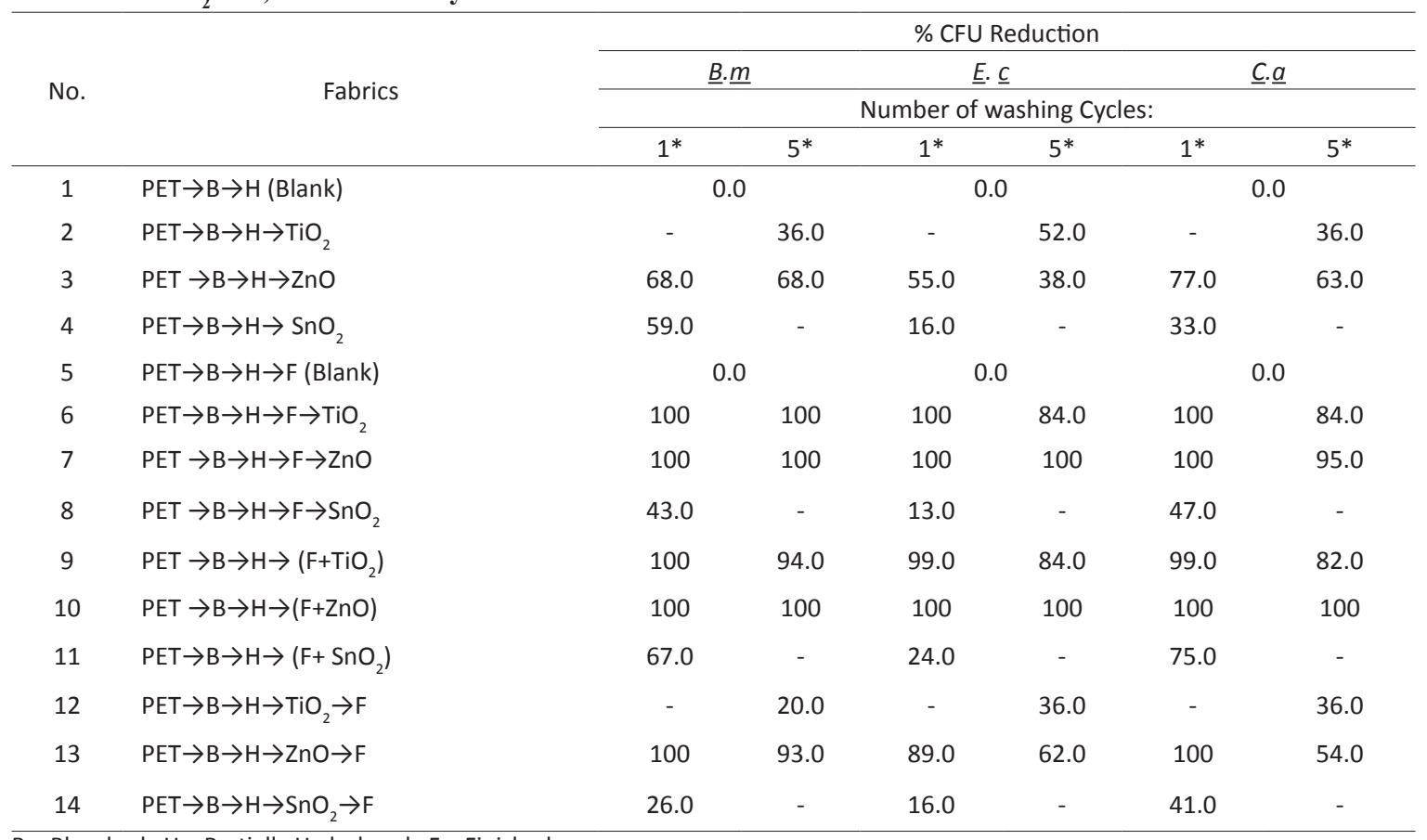

$\mathrm{B}=$ Bleached $\mathrm{H}=$ Partially Hydrolyzed $\mathrm{F}=$ Finished

Treatment Conditions: Pad-Dry-Cure Method

$\left[\mathrm{TiO}_{2}\right]$, and [ZnO], 0.5\%; Curing Temperature, $150^{\circ} \mathrm{C}$; Curing Time, $10 \mathrm{~min}$.,

$\left[\mathrm{SnO}_{2}\right], 0.5 \%$; Curing Temperature, $130^{\circ} \mathrm{C}$; Curing Time, 5 min.,

Finishing Conditions:

[Sedco Finish], $20.0 \mathrm{~g} / \mathrm{l}$; Curing Temperature, $160^{\circ} \mathrm{C}$; Curing Time, 3.0 min.,

* After 1 and 5 washing Cycles; AATCC Test Method (61-1989).

Egypt. J. Chem. 60, No. 6 (2017) 
carrying final finishing process using pad-drycure method.

\section{Ultraviolet protection properties}

The effect of the sequences of finishing wet operation on UV protection properties of bleached and partially hydrolysed PET fabrics loaded with $\mathrm{TiO}_{2}, \mathrm{ZnO}$ and $\mathrm{SnO}_{2}$ NPs was investigated. The obtained data listed in Table 5 indicate the following:

1- In general $\mathrm{TiO}_{2}$ and $\mathrm{ZnO}$ NPs are able to impart bleached and partially hydrolyzed PET fabrics UV protection properties compared to unloaded ones. On the contrary, the loading with $\mathrm{SnO}_{2}$ NPs did not cause any noticeable improvement in such properties.

2- It was found that, the finishing of $(\mathrm{PET} \rightarrow \mathrm{B} \rightarrow \mathrm{H})$ fabrics was not accompanied with changing UPF rating after 5 washing cycles in comparison to the unfinished fabrics.
3- The data in Table 5 indicate that, the sequence of loading the applied NPs after, during or before carrying out the finishing wet operation highly affect the UPF values of such fabrics as follows:

a- Loading the fabrics with $\mathrm{TiO}_{2}$ NPs before, during or after finishing wet operation leads to imparting PET fabrics good UV protection properties even after 5 standard washing cycles. The best result $(\mathrm{UPF}=22.5)$ was obtained after loading $\mathrm{TiO}_{2}$ simultaneously during the finishing wet operation.

b- Loading $\mathrm{PET} \rightarrow \mathrm{B} \rightarrow \mathrm{H}$ fabrics with $\mathrm{ZnO}$ NPs after, or during finishing operation causes a substantial increase in UPF $(50+, 47)$ even after 5 washing cycles.

c- Based on the listed data in Table 5, one can conclude that loading $\mathrm{ZnO}$ NPs after carrying the final finishing seems to be the ideal method

TABLE 5. Ultraviolet Protection Factor (UPF) of bleached and partially hydrolyzed PET fabrics loaded with $\mathrm{TiO}_{2}$, $\mathrm{ZnO}$ and $\mathrm{SnO}_{2} \mathrm{NPs}$.

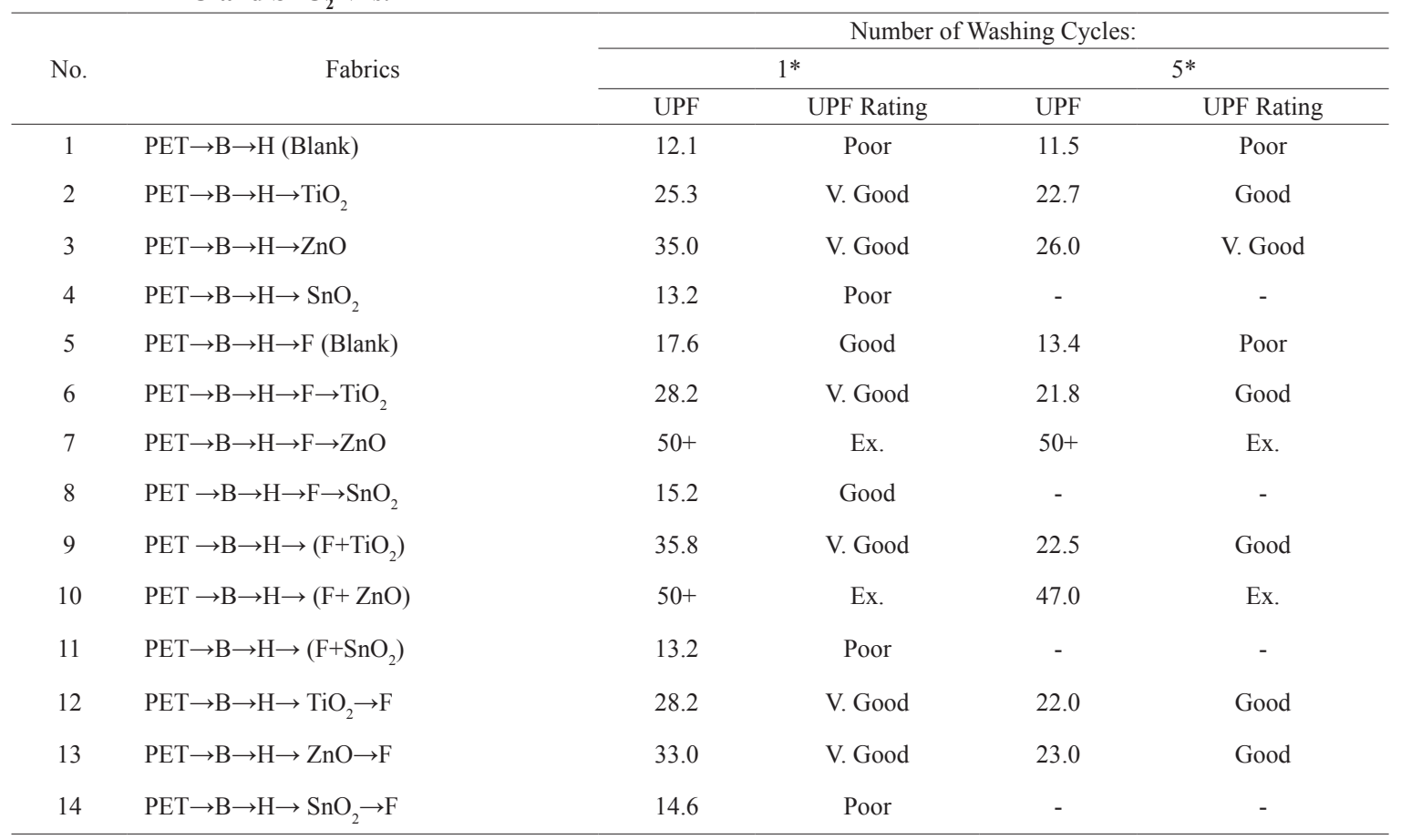

$\mathrm{B}=$ Bleached $\mathrm{H}=$ Partially Hydrolyzed $\mathrm{F}=$ Finished

Treatment Conditions: Pad-Dry-Cure Method

[ $\mathrm{TiO}_{2}$ ], and [ZnO], 0.5\%; Curing Temperature, $150^{\circ} \mathrm{C}$; Curing Time, $10 \mathrm{~min}$.,

$\left[\mathrm{SnO}_{2}\right], 0.5 \%$; Curing Temperature, $130^{\circ} \mathrm{C}$; Curing Time, 5 min.,

Finishing Conditions:

[Sedco Finish], $20.0 \mathrm{~g} / \mathrm{l}$; Curing Temperature, $160^{\circ} \mathrm{C}$; Curing Time, $3.0 \mathrm{~min}$.,

* After 1 and 5 washing Cycles; AATCC Test Method (61-1989). 
for obtaining PET fabrics with excellent UPF, even after 5 standard washing cycles.

\section{Conclusion}

The present subject covers the effect of wet processing operations (bleaching, dyeing, finishing) on functional properties imparted to PET fabrics loaded with different metal oxides NPs. This will be demonstrated in three successive articles. The aim of the present article is to investigate the effect of finishing wet operation and its sequences on functional performances imparted to bleached and partially hydrolyzed fabrics by loading with $\mathrm{TiO}_{2}, \mathrm{ZnO}$ and $\mathrm{SnO}_{2}$ NPs. Characterization of the finished fabrics was carried out through SEM, EDX and FT-IR. The obtained results reveal that, $\mathrm{TiO}_{2}, \mathrm{ZnO}$ and $\mathrm{SnO}_{2}$ are chemically bonded to PET fabrics, and that, the finishing wet operation has no effect on this interaction. The antimicrobial activity of loaded and finished PET fabrics was tested. It has been found that, loading PET fabrics with $\mathrm{TiO}_{2}$ and $\mathrm{ZnO}$ during or after carrying final finishing process paves the way for imparting outstanding antimicrobial activity even after five washing cycles, indicating excellent laundering durability. It was also found that the sequence of loading NPs after or during or before finishing wet operation highly affect the UPF values. Based on the abovementioned, one can conclude the feasibility of carrying out such modification on the wet processing line for PET fabrics.

\section{Acknowledgment}

The authors are grateful to the National Research Centre (NRC) for financial support in the Research Project No 10160001.

\section{References}

1. Fu G. , Vary P. and Lin C.T. , Anatise $\mathrm{TiO}_{2}$ nanocompsities for antimicrobial coatings. J Phys Chem., B109, 8889 - 8898 (2005).

2. Han K. and Yu M., Study of the preparation and properties of UV- blocking fabrics of $\mathrm{PET} / \mathrm{TiO}_{2}$ nanocomposite prepared by in situ polycondensation. J Appl Polym Sci, 100, 1983 1988 (2006).

3. Bozzi A., Yuranova T. and Kiwi J., Self- cleaning of wool, polyamide and polyester textiles by $\mathrm{TiO}_{2}$ - rutile modification under daylight irradiation at ambient temperature. J Photochem and Photobiology A: Chemistry, 172, 27- 43 (2005).

Egypt. J. Chem. 60, No. 6 (2017)
4. Mihailovic D., Saponjic Z., Radoicic, M. Radetic T., Jovancic, P. Nedeljkovic and J. Radetic, M. Functionalization of polyester fabrics with alginates and $\mathrm{TiO}_{2}$ nanoparticles. Carbohydrate Polymers, 97, 526-532 (2010).

5. Kathirvelu S. , Dsouza L. , Dhurai B. , UV protection finishing of textile using $\mathrm{ZnO}$ nanoparticles. Indian Journal of Fiber and Textile Research, 34, September, 267- 273 (2009).

6. Xia X. , Jiang S. , Li X. , Wei Q. and Dang X., Photo catalytic activity, surface morphology and mechanical properties of atmospheric- plasma treated of HT PET Fibers with $\mathrm{SnO}_{2}$ coating. $J$ Fiber Bioengineering and Informatics, 4, 199 - 208 (2011).

7. Lee H. J., Yeo S. Y . and Jeang S. H. , Antibacterial effect of nanosized silver colloidal solution on textile fabrics. J. Mater. Sci., 38, 2199-2204 (2003).

8. Xin J. H., Daoud W. A. and Kong Y. Y. , A new approach to UV blocking treatment for cotton fabrics. Textile Res J, 74, 97- 100 (2004).

9. Yadav A. , Prasad V. , Kathe A. A., Rai S., Yadav D. , Sundaramoorthy C. and Vigneshwaran N., Functional finishing in cotton fabrics using zinc oxide nanoparticles. Bull Mater Sci., 29, 641-645 (2006).

10. Wong Y.W. H., Yuen C.W. M. , Leung M.Y. S. , Ku S. K. A. and Lam H. L. I., Selected applications of nanotechnology in textiles. AUTEX Res. J., 6, 1-10 (2006).

11. Ilic V. , Saponjic Z., Vodnik V., Molina R., Dimitrijevic S., Jovancic P. , Nedeljkovic J. , and Radetic M. , Antifungal efficiency of corona pretreated polyester and polyamide fabrics loaded with Ag nanoparticles. J. Mater Sci., 44, 39833990 (2009).

12. Onsuratoom S., Rujiravanit R., Sreethawong I. and Tokura S., Silver loading on DBD plasmamodified woven PET surface for antimicrobial property improvement. Plasma Chem Plasma Process 30, 191- 206 (2010).

13. Shalaby S. E., Abo El- Ola S. M., Al- Balakocy N. G. , Beliakova M. K. and Afify H. , Effect of surface activation method of PET and PET/C blended fabrics on its functional finishing with $\mathrm{TiO}_{2}$ nanoparticles. J. Appl Sci Res, 9, 1731- 1741 (2013).

14. Kiwi D. and Pulgarin C. , Innovative self- cleaning and bactericide textiles. Catalysis Today, 151, 2- 7 (2010).

15. Mejia M . I., Marin M., Restrepo G. , Pulgarin C., Kiwi J. , Photocatalytic evaluation of $\mathrm{TiO}_{2} /$ Nylon 
systems prepared at different impregnation Times. Catalysis Today, 161, 15-22 (2011).

16. Shalaby S. E. , Al- Balakocy N. G. , Abo El- Ola S. M. and El shafei A. M. , Effect of surface activation of Nylon -6 fabrics by plasma and grafting with vinyl monomers on its functional finishing with $\mathrm{TiO}_{2}$ nanoparticles. J. Appl Sci. Res. 9 , 1743- 1753 (2013).

17. Shalaby S. E. , Al- Balakocy N. G., Abo El- Ola, S. M., Beliakova M. K. and Elshafei A. M., Functional finishing of polyester and polyester / cotton blended fabrics with $\mathrm{ZnO}$ nanoparticles. Intern J Appl Chemistry, 10, 77- 93 (2014).

18. Becheri A., Durr M. and LoNostra P. , Synthesis and characterization of zinc oxide nanoparticles. Application to textiles as UV- absorbers.J. Nanopart Res 10, 679 - 685 (2008).

19. Dastierdi R. , Montazer M. and Shahasavan S. A. , Novel technique for producing durable multifunctional textiles using nanocomposite.
Coating, 81, 32-41 (2010).

20. Shalaby S. E. , Al- Balakocy N. G. and Abo ElOla S. M. , Alkali treatment of polyethyleneglycol modified polyethylene terephthalate fabrics. $J$ of Textile Association, May- June 31-37 (2007).

21. Daul, G., Rinhandt, R. M. and Reid, J. D. Preparation of soluble yarns by the carboxymethylation of cotton. Textile Res. J. 23,19 - 726 (1953) 7.

22. krishnakumart T. , Pinna N. , Prasanna Kumari K., Perumal K. and Jayaprakash R., Microwaveassisted synthesis and characterization of tin oxide nanoparticles, Materials Letters, 62 3437-3440 (2008).

23. Qi K. , Xin J. H. , Daoud W. A. and Mak C. L., Functionalizing of polyester fiber with self-cleaning property using anatase $\mathrm{TiO}_{2}$ and low temperature plasma treatment. International Journal of Applied Ceramic Technology, 4, 554-563(2007).

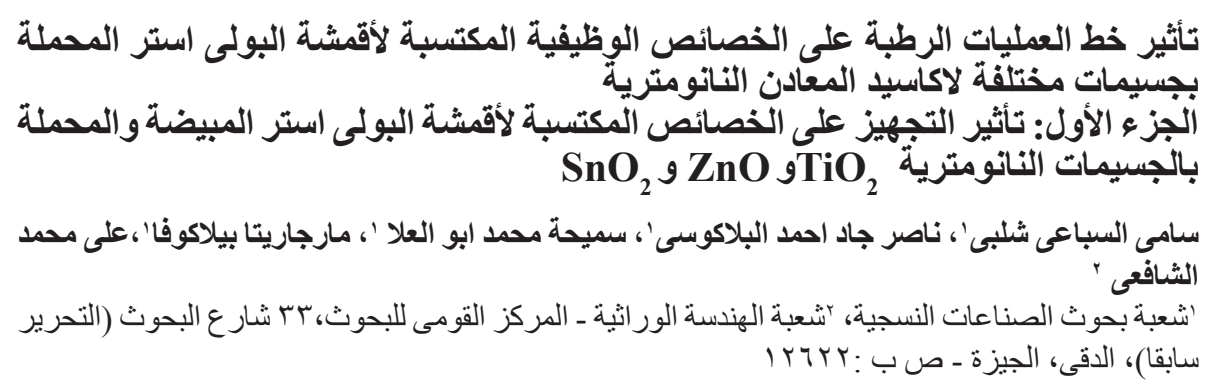

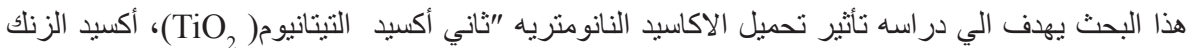
(ZnO)

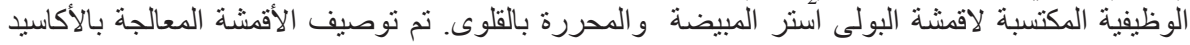

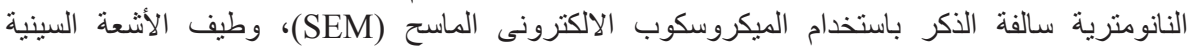

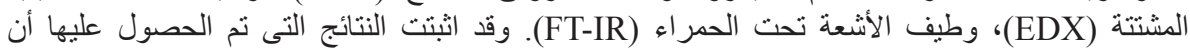

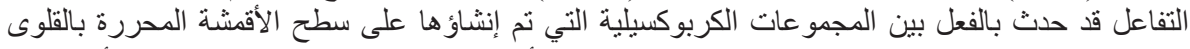

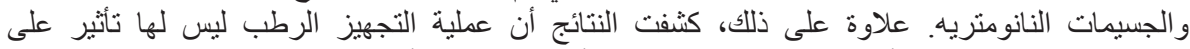

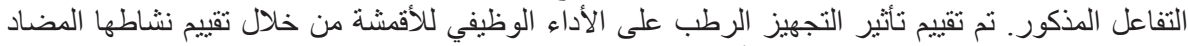

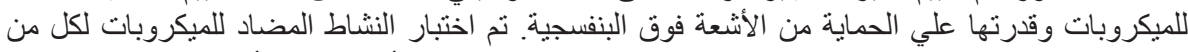

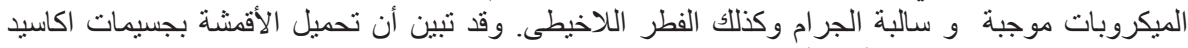

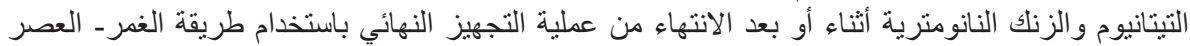

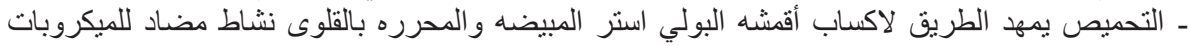
وكذلك قدره علي الحمايه من الاشعه فوق البنفسيجيه حتى بعد خمس دورات غسيل بالطريقة القياسية. 